Assurances et gestion des risques

Insurance and Risk Management

\title{
Le renvoi : un instrument de défense important dans les poursuites Américaines contre les Canadiens
}

\section{Michael L. Forte}

Volume 84, numéro 3-4, décembre 2017

URI : https://id.erudit.org/iderudit/1043361ar

DOI : https://doi.org/10.7202/1043361ar

Aller au sommaire du numéro

Éditeur(s)

Faculté des sciences de l'administration, Université Laval

ISSN

1705-7299 (imprimé)

2371-4913 (numérique)

Découvrir la revue

Citer ce document

Forte, M. L. (2017). Le renvoi : un instrument de défense important dans les poursuites Américaines contre les Canadiens. Assurances et gestion des risques / Insurance and Risk Management, 84(3-4), 165-168.

https://doi.org/10.7202/1043361ar

Tous droits réservés $\odot$ Faculté des sciences de l'administration, Université Laval, 2018
Ce document est protégé par la loi sur le droit d'auteur. L'utilisation des services d'Érudit (y compris la reproduction) est assujettie à sa politique d'utilisation que vous pouvez consulter en ligne.

https://apropos.erudit.org/fr/usagers/politique-dutilisation/ 


\section{LE RENVOI: UN INSTRUMENT DE DÉFENSE IMPORTANT DANS LES POURSUITES AMÉRICAINES CONTRE LES CANADIENS}

Michael L. FORTE1

Aux États-Unis, les demandeurs pour les cas de blessures corporelles déposent habituellement leurs procès dans le système judiciaire étatique. Le système judiciaire étatique est plus avantageux pour les demandeurs, alors que le système judiciaire fédéral est plus avantageux pour les défendeurs. Au cours de la procédure de renvoi, les Canadiens poursuivis en justice aux États-Unis peuvent facilement retirer l'affaire hors du tribunal étatique et la réinsérer dans un tribunal fédéral. Cet article explique les exigences pour le retrait et ses nombreux avantages de défense.

Tout d'abord, quelques informations contextuelles. Les États-Unis ont deux systèmes judiciaires parallèles. Chacun des 50 États possède son propre système, composé généralement de tribunaux de première instance, de cours d'appel intermédiaires et d'une cour suprême d'État. De plus, le gouvernement fédéral dispose d'un système distinct à l'échelle nationale. Il se compose de tribunaux de district situés dans chacun des États, des cours d'appel intermédiaires couvrant plusieurs États et la Cour suprême des États-Unis.

Les deux systèmes traitent différents types d'affaires. Mais certaines affaires - tels que les cas de blessures corporelles - peuvent être traitées par l'un ou l'autre. Un défendeur peut retirer une affaire d'un État à l'autre lorsque (1) il ou elle est ressortissant(e) d'un pays ou d'un État différent que celui du demandeur et (2) le montant en polémique est supérieur à 75000 \$. 
Un défendeur canadien répond facilement à la première exigence, car les poursuites américaines sont presque toujours déposées par des citoyens américains. La deuxième exigence peut être satisfaite par des notices représentant plus de 75000 \$ en factures médicales et/ou des salaires perdus. Les avantages de la cour fédérale sont nombreux.

\section{Recouvrement anticipé des informations sur les dommages}

Les règles de procédure fédérales exigent que, au début de l'affaire, les parties échangent automatiquement certaines catégories d'informations sans la demande de l'autre partie. Pour le demandeur, cela signifie divulguer un calcul de chaque catégorie de dommages-intérêts. Ces catégories incluent généralement des dossiers médicaux passés et futures, des salaires perdus passés et futurs, ainsi que des préjudices moraux passés et futurs.

\section{Obligation permanente de mettre à jour les réponses à la divulgation}

Si un demandeur au tribunal fédéral continue son traitement médical pendant toute la durée de l'affaire, il ou elle doit continuellement fournir l'information et les dossiers médicaux mis à jour au défendeur sans avoir été invité(e). Si un demandeur obtient un nouveau traitement et ne fournit pas les informations correspondantes, le tribunal pourrait empêcher le demandeur de présenter lesdites informations au procès.

\section{Moins de conflits de divulgations}

Bien que les requêtes de divulgation soient courantes dans les tribunaux étatiques, les tribunaux fédéraux n'aiment pas ces requêtes. Les avocats exerçant dans le tribunal fédéral sont plus susceptibles de s'abstenir à proposer des débats en faveur d'un travail informel sur le problème. Lorsque les requêtes de divulgation sont déposées, les tribunaux fédéraux émettent généralement des décisions fondées sur les observations écrites au lieu de tenir de plaidoiries orales. Sans plaidoiries orales, les avocats demandeurs sont tenus aux exigences de la loi et sont privés de la possibilité de faire une ouverture émotionnelle lors d'une audience. 


\section{Respect strict des délais}

Lorsqu'un tribunal fédéral fixe un délai, il tiendra les parties à ce délai sauf cas d'un type de catastrophe intervenue (I'd prefer "sauf cas de forces majeures"). Par exemple, le demandeur qui dépose des informations à l'intention des experts avec un ou deux jour(s) de retard pourrait très bien faire en sorte que le tribunal s'oppose à ce que ces experts témoignent. À l'inverse, les recours judiciaires étatiques typiques sont une prolongation du délai de divulgation ou de la poursuite du procès.

\section{Divulgation d'experts pour les médecins traitants}

Dans le tribunal étatique, les médecins traitants ne sont pas considérés comme des experts retenus, même si les médecins peuvent avoir une relation étroite avec le procureur du demandeur. En tant que tel, le demandeur n'est pas tenu de divulguer les opinions auxquelles les médecins témoigneront au procès. Dans le tribunal fédéral, le demandeur est tenu de divulguer un résumé des faits et opinions auxquels les médecins devraient témoigner. Dans des circonstances inhabituelles, le tribunal fédéral limitera le témoignage des médecins aux avis divulgués.

\section{Respect strict des exigences de fond}

Les règles de procédure fédérale énoncent des exigences strictes pour la divulgation des opinions des experts retenus. Le fait de ne pas satisfaire à ces exigences pourrait très bien signifier que l'expert serait empêché de témoigner au procès.

\section{Possibilité accrue de jugement sommaire}

Généralement, les tribunaux fédéraux sont plus enclins à accorder un jugement sommaire que les tribunaux étatiques.

\section{Groupe de juré plus engagé}

Dans de nombreux tribunaux étatiques, les jurés potentiels sont choisis à partir des bases de données de permis de conduire. Au tribunal fédéral, les jurés potentiels sont choisis parmi les électeurs inscrits. 
L'inscription des électeurs indique vraisemblablement un intérêt accru pour le service gouvernemental et une telle personne est plus susceptible d'être pleinement engagée dans son service du jury.

\section{Les demandeurs le détestent}

Si les avocats demandeurs préfèrent le tribunal fédéral, ils y déposeraient leurs poursuites. Ils sont mal informés sur le tribunal fédéral du fait qu'ils ont tendance à éviter les litiges fédéraux. Ce manque de familiarité peut engendrer un manque de confiance. Dans certains cas, ce manque de confiance peut entraîner une résolution plus raisonnable que l'on n'aurait pu l'imaginer.

\section{NOTE}

1. Michael L. Forte est associé au Tampa, bureau de Rumberger en Floride, Kirk \& Caldwell, P.A. Sa pratique couvre les domaines de la défense contre les accidents et la responsabilité du produit. 